Check for updates

Cite this: J. Mater. Chem. B, 2021 9, 4929

Received 9th March 2021

Accepted 2nd June 2021

DOI: $10.1039 / \mathrm{d} 1 \mathrm{tb} 00505 \mathrm{~g}$

rsc.li/materials-b

\title{
Design of hybrid biocatalysts by controlled heteroaggregation of manganese oxide and sulfate latex particles to combat reactive oxygen species $\dagger$
}

\author{
Nizar B. Alsharif, ${ }^{a}$ Katalin Bere, ${ }^{a}$ Szilárd Sáringer, ${ }^{a b}$ Gergely F. Samu, (D) $^{\mathrm{b}}$ \\ Dóra Takács, ${ }^{a}$ Viktória Hornok ${ }^{\mathrm{b}}$ and Istvan Szilagyi (D) *ab
}

\begin{abstract}
The preparation of an antioxidant hybrid material by controlled heteroaggregation of manganese oxide nanoparticles $\left(\mathrm{MnO}_{2} \mathrm{NPS}\right)$ and sulfate-functionalized polystyrene latex (SL) beads was accomplished. Negatively charged $\mathrm{MnO}_{2}$ NPs were prepared by precipitation and initially functionalized with poly(diallyldimethylammonium chloride) (PDADMAC) polyelectrolyte to induce charge reversal allowing decoration of oppositely charged SL surfaces via simple mixing. The PDADMAC-functionalized $\mathrm{MnO}_{2}$ NPS (PMn) aggregated with the SL particles leading to the formation of negatively charged, neutral and positively charged (SPMn) composites. The charge neutralization resulted in rapidly aggregating dispersions, while stable samples were observed once the composites possessed sufficiently high negative and positive charge, below and above the charge neutralization point, respectively. The antioxidant assays revealed that $\mathrm{SL}$ served as a suitable substrate and that the PDADMAC functionalization and immobilization of $\mathrm{MnO}_{2} \mathrm{NPs}$ did not compromise their catalase (CAT) and superoxide dismutase (SOD)-like activities, which were also maintained within a wide temperature range. The obtained SPMn composite is expected to be an excellent candidate as an antioxidant material for the efficient scavenging of reactive oxygen species at both laboratory and larger scales, even under harsh conditions, where natural antioxidants do not function.
\end{abstract}

\section{Introduction}

Despite being exceptional catalysts, natural enzymes suffer from significant sensitivity to such operational conditions as $\mathrm{pH}$ and temperature. ${ }^{1}$ Under undesignated conditions, structures of proteins can denature and permanently lose their catalytic activity. Moreover, enzyme production and purification processes are time consuming and are often considerably expensive. ${ }^{2}$ These drawbacks have paved the way to cost-effective and efficient artificial enzyme catalysts as alternatives to their natural counterparts. These enzyme mimics have diverse structures such as metal complexes, cyclodextrins, polymers, and more importantly nanomaterials. ${ }^{3-5}$ Unlike natural enzymes, nanomaterial-based artificial enzymes (nanozymes) are easy and cheap to prepare and possess catalytic activity often well outside the operational

\footnotetext{
${ }^{a}$ MTA-SZTE Lendület Biocolloids Research Group, University of Szeged,

H-6720 Szeged, Hungary.E-mail: szistvan@chem.u-szeged.hu

${ }^{b}$ Interdisciplinary Excellence Center, Department of Physical Chemistry and

Materials Science, University of Szeged, H-6720 Szeged, Hungary

$\dagger$ Electronic supplementary information (ESI) available: Material composition data, dispersions characteristics, deconvolution of XPS peaks as well as TEM and SEM images. See DOI: 10.1039/d1tb00505g
}

conditions of the mimicked natural biocatalysts, owing to their large surface area, structural stability and the possibility to tune the physico-chemical properties of such nanomaterials. ${ }^{4,6,7}$

In this way, nanomaterials possessing antioxidant activities have been widely explored in attempt to replace natural radical scavenging enzymes. ${ }^{8-11}$ Since the early reports on superoxide dismutase (SOD) mimicry by fullerene derivatives, ${ }^{12,13}$ extensive research has been reported in the literature on various antioxidant nanozymes of diverse structures and catalytic roles. ${ }^{4,6}$ These include metallic nanoparticles such as $\mathrm{Ag},{ }^{14} \mathrm{Au},{ }^{15} \mathrm{Pt},{ }^{16}$ and $\mathrm{Pd} ;{ }^{17}$ metal oxides including $\mathrm{Co}_{3} \mathrm{O}_{4},{ }^{18} \mathrm{CeO}_{2},{ }^{9,19}$ and $\mathrm{CuO}^{20}$ nanospheres as well as $\mathrm{V}_{2} \mathrm{O}_{5}$ nanowires; ${ }^{21}$ metal chalcogenides such as FeS, ${ }^{22} \mathrm{MoSe}_{2},{ }^{11} \mathrm{MoS}_{2},{ }^{23}$ and $\mathrm{WS}_{2}{ }^{24}$ nanosheets; carbon derivatives like fullerenes, carbon nanotubes, nanodots and metal-organic frameworks. ${ }^{6,10,25,26}$

Among these nanozymes, nanostructured $\mathrm{MnO}_{2}$ has been reported to possess both SOD and catalase (CAT)-like activities. ${ }^{27,28}$ Biocompatibility and biodegradability of $\mathrm{MnO}_{2}$ materials have been confirmed as well. ${ }^{29-31}$ They were applied in numerous fields such as energy storage, ${ }^{32,33}$ chemotherapy, ${ }^{34}$ sensing ${ }^{35}$ catalysis, ${ }^{36,37}$ and drug delivery. ${ }^{38}$ However, $\mathrm{MnO}_{2}$ nanoparticles, as the case with most metal oxides, are water-insoluble materials with aqueous colloidal 
stability that is heavily dependent on the experimental conditions such as temperature, $\mathrm{pH}$, ionic strength, and the presence of stabilizing agents (e.g., surfactants or polymers). ${ }^{39}$ Often, the industrial and biological applications of these nanomaterials such as catalysis and drug delivery might normally be carried out at $\mathrm{pH}$ or ionic strength conditions where such particles are mostly unstable or too small to separate from the reaction mixture after the catalytic reaction is terminated. Thus, a versatile use of such materials necessitates a full understanding of their colloidal behavior.

Therefore, formulation of $\mathrm{MnO}_{2}$ on larger support particles is desirable to improve their colloidal stability, to ease separation and to concentrate them in a smaller space to achieve efficient local catalytic activity. In our previous study, it was shown that antioxidant Prussian blue particles can be successfully immobilized on amidine latex particles of significantly larger size. ${ }^{39}$ This prompted the idea to decorate supporting latex particles with manganese oxide nanoparticles, which are known as multifunctional materials in scavenging of reactive oxygen species. Heteroaggregation of differently sized particles in aqueous dispersions has been utilized to investigate fundamental processes and also to prepare various composite materials. ${ }^{40-43}$ However, to the best of our knowledge, this is the first time, when broad-spectrum antioxidant $\mathrm{MnO}_{2} \mathrm{NPs}$ and latex particles are used for such a purpose.

Therefore, in the present work, polyelectrolyte functionalized $\mathrm{MnO}_{2}$ NPs (PMn) were synthesized and their heteroaggregation with sulfate latex (SL) particles was investigated in a wide range of PMn-to-SL mass ratio. Charging and aggregation processes were explored by electrophoretic and dynamic light scattering to establish the colloidal stability regimes, while the structural features were studied with spectroscopy and electron microscopy methods. The SOD and CAT-like activities of the bare $\mathrm{MnO}_{2} \mathrm{NPS}$ and the obtained SPMn particles were extensively investigated at different temperatures. The preparation and catalytic activity assessment are illustrated in Scheme 1.

\section{Experimental section}

\section{Materials}

$\mathrm{H}_{2} \mathrm{O}_{2}(30 \% \mathrm{~m} / \mathrm{m}), \mathrm{HCl}(37 \% \mathrm{~m} / \mathrm{m}), \mathrm{NaCl}(\sim 99.5 \%)$, acetone $(\sim 99.8 \%)$, absolute ethanol $(\geq 99.8 \%)$, NaOH (AnalaR

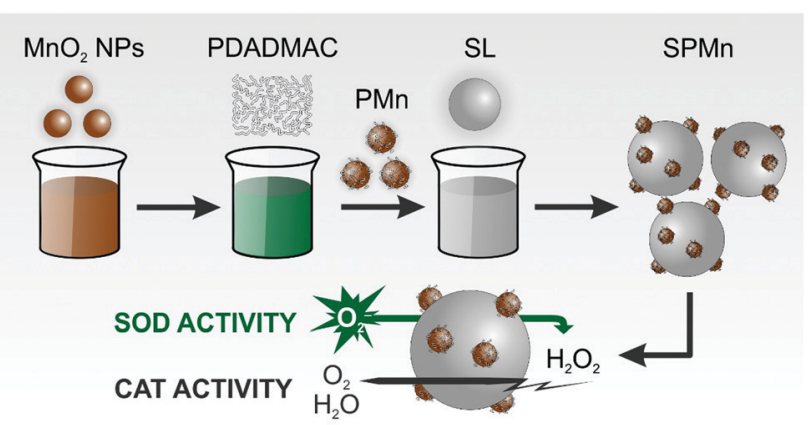

Scheme 1 Illustration of the synthesis and enzymatic activity of the SPMn hybrid composite.
NORMAPUR $\left.{ }^{\circledR}\right)$, and $\mathrm{K}_{2} \mathrm{~S}_{2} \mathrm{O}_{8}\left(98 \%\right.$, AnalaR NORMAPUR $\left.{ }^{\circledR}\right)$ were purchased from $\mathrm{VWR}^{\mathrm{TM}}$, while $\mathrm{KMnO}_{4}$ (reagent grade, 99\%), nitro blue tetrazolium chloride (90\%), styrene (99\%), and polyvinylpyrrolidone $\left(58000 \mathrm{~g} \mathrm{~mol}^{-1}\right.$ ) were bought from Acros Organics $^{\mathrm{TM}}$. Oleic acid (90\%, technical grade), PDADMAC (200000-350000 g mol $\mathrm{g}^{-1}, 20 \mathrm{wt} \%$ ), and xanthine oxidase (lyophilized powder, 0.4-1.0 units per $\mathrm{mg}$ protein) were obtained from Sigma-Aldrich. Xanthine (99\%) was purchased from Alfa Aesar. Phosphate buffer solution was prepared using $\mathrm{NaH}_{2} \mathrm{PO}_{4}$ (99\%, anhydrous) and $\mathrm{Na}_{2} \mathrm{HPO}_{4}(\geq 99 \%$, GPR RECTAPUR $^{\circledR}$ ), which were obtained from Acros Organics ${ }^{\mathrm{TM}}$ and VWR $^{\mathrm{TM}}$, respectively. Hellmanex ${ }^{\circledR}$ III cleaning agent was bought from Hellma while Spectra/Por ${ }^{\mathbb{B}} 6$ dialysis membrane tubing was obtained from SpectrumLabs. The $\mathrm{pH}$ was kept at $(9.0 \pm 0.2)$ throughout all experiments, unless indicated otherwise. The $\mathrm{VWR}^{\mathrm{TM}}$ Puranity TU 3 UV/UF+ system was used to obtain ultrapure water, which was further filtered using PVDF-based $0.1 \mu \mathrm{m}$ syringe filters purchased from MILLEX-VV. The ionic strength was adjusted by $\mathrm{NaCl}$ solutions.

\section{Preparation of $\mathrm{MnO}_{2} \mathrm{NPs}$ and SL}

The glassware were carefully cleaned with Hellmanex ${ }^{\circledR}$ III and concentrated $\mathrm{HCl}$ solution. The $\mathrm{MnO}_{2}$ NPs were prepared by following a reported procedure. ${ }^{28}$ Briefly, $1.0 \mathrm{~g}$ of $\mathrm{KMnO}_{4}$ was dissolved in $500 \mathrm{~mL}$ of ultrapure water and the resulting solution was vigorously stirred for $30 \mathrm{~min}$. Then $10 \mathrm{~mL}$ of oleic acid was added, and the reaction mixture was left under vigorous stirring at $28{ }^{\circ} \mathrm{C}$ for $5 \mathrm{~h}$. The formed black precipitate was then collected by centrifugation and washed with ultrapure water and ethanol to remove unreacted compounds. The obtained solid material was dried for $10 \mathrm{~h}$ at $80{ }^{\circ} \mathrm{C}$. Finally, the nanoparticles were dispersed in ultrapure water to obtain a $10 \mathrm{~g} \mathrm{~L}^{-1}$ stock. The SL particles were prepared by emulsifier-free emulsion polymerization using $\mathrm{K}_{2} \mathrm{~S}_{2} \mathrm{O}_{8}$ as an initiator. ${ }^{44}$ In a typical synthesis, $12.1 \mathrm{~g}$ styrene and $60.5 \mathrm{mg}$ polyvinylpyrrolidone (PVP) were added to $100 \mathrm{~mL}$ of deionized water at room temperature in a $250 \mathrm{~mL}$ three-neck round bottom flask, that is kept in an oil bath under $\mathrm{N}_{2}$ atmosphere. The mixture was then stirred for $30 \mathrm{~min}$ at $400 \mathrm{rpm}$, and the temperature was increased progressively to $70{ }^{\circ} \mathrm{C}$. Subsequently, $300 \mathrm{mg}$ of $\mathrm{K}_{2} \mathrm{~S}_{2} \mathrm{O}_{8}$ were dissolved in $20 \mathrm{~mL}$ of deionized water, and the resulting solution was added to the reaction mixture that is then kept for $24 \mathrm{~h}$ at $70{ }^{\circ} \mathrm{C}$. After the mixture was cooled to room temperature, the remnant styrene and PVP were removed by repeated washing, centrifugation, and redispersing. The product was washed by pure water and ethanol and dialyzed against water for one day. The final SL concentration was $50 \mathrm{~g} \mathrm{~L}^{-1}$, obtained by diluting the mother liquor.

\section{Preparation of PMn and SPMn particles}

The immobilization of PDADMAC on the surface of $\mathrm{MnO}_{2} \mathrm{NPs}$ was achieved by simply mixing proper volumes of PDADMAC and $\mathrm{MnO}_{2}$ NPs dispersions, followed by addition of $\mathrm{NaCl}$ solution to fix the ionic strength. The concentration of $\mathrm{MnO}_{2}$ NPs was fixed, while the PDADMAC dose (in mg PDADMAC/g $\mathrm{MnO}_{2}$ NPs) was altered until overall positively charged PMn 
particles were obtained. Similar procedure was followed during preparation of SPMn, where the concentration of SL was fixed as the dose of positively charged PMn (in mg PMn/g SL) was altered. After the addition of proper volumes of PMn and SL, the ionic strength was fixed by $\mathrm{NaCl}$ solution. In both cases, the origin of the driving forces was mainly electrostatic attraction between the oppositely charged PDADMAC and $\mathrm{MnO}_{2} \mathrm{NPs}$ as well as between PMn and SL under the applied experimental conditions. The final SPMn dispersions were homogenized by ultrasonication.

\section{Electrophoretic light scattering}

Zeta potential values were determined using an Anton Paar Litesizer $^{\mathrm{TM}} 500$ device equipped with a $658 \mathrm{~nm}$ wavelength laser source, with the applied voltage kept at $200 \mathrm{~V}$ throughout all electrophoretic light scattering measurements. The initially measured electrophoretic mobilities were converted into zeta potentials by the Smoluchowski equation. ${ }^{45}$ First, the pH-dependence of zeta potential of $\mathrm{MnO}_{2} \mathrm{NPs}$ and SL was studied in the $\mathrm{pH}$ range 3-11 at constant ionic strength of $1 \mathrm{mM}$. In a typical procedure, two $50 \mathrm{ppm}$ stock $\mathrm{MnO}_{2}$ NPs dispersions were prepared at pH 3 and 11, respectively. Then, a series of $8 \mathrm{~mL}$ $\mathrm{MnO}_{2}$ NPs dispersions was prepared by mixing different portions of the two stocks, so that the $\mathrm{pH}$ in the series of dispersions gradually changed from 3 to 11 . After each mixing, the resulting dispersion was homogenized by vortex and its $\mathrm{pH}$ value was unambiguously measured with a WTW pH benchtop meter (inoLab ${ }^{\circledR} \mathrm{pH}$ 7310). The same procedure was followed for SL, except the concentration of two SL stocks was set at $125 \mathrm{ppm}$. For the determination of zeta potential of the SL at different salt concentrations, several 125 ppm SL dispersions were prepared with an ionic strength gradually varies between 1$1000 \mathrm{mM}$. In addition, the effect of PDADMAC dose on the charge of $\mathrm{MnO}_{2}$ NPs was obtained in the 0.1-1000 mg PDAD$\mathrm{MAC} / \mathrm{g} \mathrm{MnO}_{2}$ NPs dose range at $1 \mathrm{mM}$ ionic strength. In each sample, the $\mathrm{MnO}_{2}$ NPs concentration was kept at $100 \mathrm{ppm}$, while the amount of polyelectrolyte was adjusted to the desired dose. The effect of PMn (where the dose of adsorbed PDADMAC on $\mathrm{MnO}_{2}$ NPs results in positively charge PMn, as detailed later) on the charge of SL was studied in the dose range of $0.01-1000 \mathrm{mg}$ $\mathrm{PMn} / \mathrm{g} \mathrm{SL}$ at $1 \mathrm{mM}$ ionic strength. In all samples, the SL concentration was kept at $125 \mathrm{ppm}$, while the amount of PMn was adjusted to the desired dose. Generally, the prepared dispersions were left to equilibrate for 2 hours at room temperature. To measure the zeta potential, $700 \mu \mathrm{L}$ were withdrawn from the dispersion of interest and were transferred to an omega cuvette (Anton Paar $^{\mathrm{TM}}$ ). The zeta potential measurement was then performed at $(25.0 \pm 0.2){ }^{\circ} \mathrm{C}$ and reported as an average of 6 runs.

\section{Dynamic light scattering}

The hydrodynamic radius of the particles was measured with dynamic light scattering (DLS) using an ALV-NIBS/HPPS Particle sizer equipped with a $632.8 \mathrm{~nm}$ laser source. The scattered light was collected at $173^{\circ}$ and data analysis was based on the cumulant fit. ${ }^{46}$ The DLS sample preparation is identical to that followed in the electrophoretic part above, with the exception that each measurement was started immediately after addition of the desired volume of SL, $\mathrm{MnO}_{2} \mathrm{NPs}$, or PMn to the corresponding samples. The total volume of each sample was $2.0 \mathrm{~mL}$ and the experiments were carried out in disposable polystyrene cuvettes at $(25.0 \pm 0.2){ }^{\circ} \mathrm{C}$. Additionally, the $\mathrm{pH}$-dependence of hydrodynamic radius of $\mathrm{MnO}_{2} \mathrm{NPs}$ and SL was studied in the $\mathrm{pH}$ range 3-11 at constant ionic strength of $1 \mathrm{mM}$. In all time-resolved DLS measurements, the hydrodynamic radius versus time curves contained 30-100 measurement points for each sample depending on the aggregation rate. The colloidal stability was expressed in terms of stability ratio $(W)$ calculated with the following equation. ${ }^{47}$

$$
W=\frac{k_{\mathrm{app}(\mathrm{fast})}}{k_{\mathrm{app}}}
$$

where $k_{\text {app }}$ is the apparent aggregation rate constant and $k_{\text {app(fast) }}$ is the apparent aggregation rate constant at $1.0 \mathrm{M}$ ionic strength, at which condition the aggregation process is solely controlled by the diffusion of the particles, i.e., rapid particle aggregation occurs. The apparent aggregation rate constant was calculated from the hydrodynamic radius versus time plots as follows. $^{46}$

$$
k_{\mathrm{app}}=\frac{1}{R_{\mathrm{h}}(0)} \cdot\left(\frac{\mathrm{d} R_{\mathrm{h}}(t)}{\mathrm{d} t}\right)_{t \rightarrow 0}
$$

where $R_{\mathrm{h}}(0)$ is the hydrodynamic radius of the monomer particles and $\frac{\mathrm{d} R_{\mathrm{h}}(t)}{\mathrm{d} t}$ is the slope of the linear fit of the hydrodynamic radius versus time data points of the sample of interest. Stability ratio values close to unity indicate rapid or diffusion-controlled aggregation, while stable samples have high or not even measurable stability ratio values. In addition, the time during which half of the primary particles aggregate into dimers is called the aggregation half-time $\left(T_{1 / 2}\right)$, which was calculated using the following equation. ${ }^{48}$

$$
T_{1 / 2}=\frac{2}{k N_{0}}
$$

where $N_{0}$ is the particle number concentration and $k$ is Smoluchowski's diffusion-controlled aggregation rate constant. ${ }^{46}$

\section{Electron microscopy}

The morphologies of the particles (SL, $\mathrm{MnO}_{2} \mathrm{NPs}$, and SPMn) were analyzed by scanning (SEM, Hitachi S4700) and transmission electron microscopy (TEM, FEI Tecnai G2). In TEM sample preparation, $5 \mu \mathrm{L}$ of the particle dispersion was introduced on a copper-coated carbon mesh. Each aliquot was left to adsorb for 10 seconds. The sample grids were prepared $30 \mathrm{~min}$ before the measurements. To prepare SEM samples, $5 \mu \mathrm{L}$ volumes from each dispersion were introduced on the SEM sample holder, a piece of silicon wafer on an aluminum disk, and were left to dry for $10 \mathrm{~min}$. The sample holder is coated with $\mathrm{Au}$ thin film via sputtering before it was introduced into the microscope. 


\section{X-Ray photoelectron spectroscopy}

The X-ray photoelectron spectroscopy (XPS) measurements were performed with a SPECS instrument equipped with a PHOIBOS 150 MCD 9 hemispherical analyzer, under a mainchamber pressure in the $10^{-9}-10^{-10}$ mbar range. The analyzer was in fixed transmission mode with $40 \mathrm{eV}$ pass energy for the survey scan and $20 \mathrm{eV}$ pass energy for the high-resolution scans. Al K $\alpha$ X-ray source was used at $14 \mathrm{kV}$ and $150 \mathrm{~W}$ power. Charge referencing was done to the adventitious carbon $(284.8 \mathrm{eV})$ on the surface of the sample. For spectrum evaluation, CasaXPS commercial software package was used.

\section{Atomic force microscopy}

The SPMn composite were further investigated using a Multimode Nanoscope IIIa atomic force microscope (AFM, Digital Instruments, USA). The images were acquired in tapping mode in air at room temperature using a Si tip cantilever (Veeco Nanoprobe Tips RTESPA model) with a resonance frequency of 275-300 kHz. Height- and amplitude-mode images were recorded simultaneously with $1.0 \mathrm{~Hz}$ scan rate. Processing and analysis of the images were carried out using the off-line software Nanoscope V614r1. The sample for AFM was prepared by depositing a dilute dispersion on a freshly cleaved mica (Ted Pella, Highest Grade V1) and were left to dry at room temperature.

\section{Catalase assay}

The catalase activity of $\mathrm{MnO}_{2}$ NPs and SPMn was confirmed via the catalase assay reported elsewhere..$^{28,49}$ In the presence of catalase or its mimics, $\mathrm{H}_{2} \mathrm{O}_{2}$ breaks down into water and molecular oxygen, and the reduction in the absorbance of $\mathrm{H}_{2} \mathrm{O}_{2}$ at a wavelength of $240 \mathrm{~nm}$ is quantitatively observed with UV-Vis spectrophotometry (GENESYS ${ }^{\mathrm{TM}}$ 10S, Thermo Fischer Scientific). The concentration of $\mathrm{MnO}_{2}$ NPs or SPMn was kept constant, while the concentration of $\mathrm{H}_{2} \mathrm{O}_{2}$ was varied between 0 and $1 \mathrm{mM}$. The $\mathrm{pH}$ in the final samples was kept at $(7.0 \pm 0.1)$ using phosphate buffer. Thus, in each of the $2400 \mu \mathrm{L}$ samples, a varied volume of $\mathrm{H}_{2} \mathrm{O}_{2}$ was mixed with $1000 \mu \mathrm{L}$ of $120 \mathrm{mM}$ phosphate buffer followed by a volume of ultrapure water to obtain $2200 \mu \mathrm{L}$ sample. The cuvette was then vortexed for 10 seconds. Finally, $200 \mu \mathrm{L}$ of $\mathrm{MnO}_{2} \mathrm{NPs}$ dispersion (120 ppm) or SPMn dispersion (which is $120 \mathrm{ppm}$ in $\mathrm{MnO}_{2} \mathrm{NPs}$, at $200 \mathrm{mg}$ PDADMAC/g Mn and $100 \mathrm{PMn} / \mathrm{g} \mathrm{SL}$ ) was added and the cuvette was vortexed for 3 seconds, and then immediately introduced into the spectrophotometer, where the linear absorbance versus time plot was recorded at $240 \mathrm{~nm}$ for $10 \mathrm{~min}$. The slopes of absorbance versus time curve represent the corresponding reaction rates $(v)$ measured in absorbance unit per second. The reaction rate was converted to $\mathrm{mM} \mathrm{s}{ }^{-1}$ units using the Beer-Lambert law. The optical light path is $1 \mathrm{~cm}$ and the molar extinction coefficient of $\mathrm{H}_{2} \mathrm{O}_{2}$ is $39.4 \mathrm{M}^{-1} \mathrm{~cm}^{-1} \cdot{ }^{28}$ Finally, the reaction rate $(\nu)$ was plotted as a function of $\mathrm{H}_{2} \mathrm{O}_{2}$ concentration ([S]) in the corresponding sample. The kinetics of enzymatic reaction was assessed by fitting the rate versus concentration data with
Michaelis-Menten model, ${ }^{50}$ as expressed in the following equation.

$$
v=\frac{v_{\max }}{K_{\mathrm{m}}+[\mathrm{S}]}
$$

where $v_{\max }$ is the maximum possible reaction rate that is independent of the substrate concentration and $K_{\mathrm{m}}$ is the Michaelis-Menten constant.

\section{Superoxide dismutase assay}

The Fridovich assay ${ }^{51}$ was used to probe the SOD activity of $\mathrm{MnO}_{2}$ NPs or SPMn. The SOD enzyme catalyzes the dismutation of superoxide radical ions. Here, the xanthine oxidation reaction, catalyzed by xanthine oxidase, generates superoxide radical ions, which react with nitroblue tetrazolium (NBT) that turns from yellow to blue upon reaction with the radicals. In the presence of SOD or a mimicking material, the generated radical ions are scavenged reducing the amount of blue product as well as the intensity of blue color, which can be monitored by UV-Vis spectrophotometry. In a typical measurement, only the $\mathrm{MnO}_{2}$ NPs or SPMn concentration was changed between 0 and $2 \mathrm{ppm}$. In the final sample, the phosphate buffer was kept at $10 \mathrm{mM}$ to adjust $\mathrm{pH}(7.0 \pm 0.1)$. Thus, in each of the $3000 \mu \mathrm{L}$ samples, $200 \mu \mathrm{L}$ xanthine $(3.0 \mathrm{mM})$ and $100 \mu \mathrm{L}$ NBT $(3.0 \mathrm{mM})$ were added to calculated volume of $\mathrm{MnO}_{2}$ NPs or SPMn dispersion, followed by addition of a portion of phosphate buffer to obtain $2700 \mu \mathrm{L}$ sample. The cuvette was then vortexed for 5 seconds. Finally, $300 \mu \mathrm{L}$ xanthine oxidase $\left(1.5 \mathrm{~g} \mathrm{~L}^{-1}\right)$ was added to the sample before it was immediately vortexed for 5 seconds and introduced into the spectrophotometer. The change in absorbance with time was recorded for $6 \mathrm{~min}$ at $565 \mathrm{~nm}$ wavelength. Furthermore, eight blanks were also measured, each of which was prepared by adding all reagents mentioned except $\mathrm{MnO}_{2}$ NPs or SPMn, with additional volume of phosphate buffer solution to keep the final concentrations identical. The inhibition curve is created by plotting the inhibition ( $I$ ) of the radical-NBT reaction for each sample against the final $\mathrm{MnO}_{2} \mathrm{NPs}$ or SPMn concentration in the corresponding sample. The inhibition can be calculated as follows.

$$
I=\frac{\Delta A_{0}-\Delta A_{\mathrm{s}}}{\Delta A_{0}} \times 100
$$

where $\Delta A_{\mathrm{s}}$ is the change in absorbance during the $6 \mathrm{~min}$ measurement time and $\Delta A_{0}$ is the averaged value of the absorbance change for the eight blank samples. The concentration of the nanozyme that causes $50 \%$ inhibition of is called the $\mathrm{IC}_{50}$ value. During the assays, light scattering by the particles does contribute to the absolute value of absorbance, however, this factor was eliminated by taking the relative increase in the absorbance in the individual experiments.

\section{Results and discussion}

\section{Characterization of the $\mathrm{MnO}_{2} \mathrm{NPs}$ and SL}

The surface chemical composition of the prepared $\mathrm{MnO}_{2} \mathrm{NPs}$ was explored with XPS. The recorded survey scan, shown in 
Fig. 1, reveals the presence of $\mathrm{Mn}, \mathrm{O}, \mathrm{C}$, and $\mathrm{K}$ elements on the surface of the sample. The quantitative XPS composition analysis resulted in the following composition of the sample: 23.4 at\% Mn, 19.5 at\% C, 1.3 at\% K and 55.8 at\% O (Table S1, see ESI $\dagger$ ). The large number of different oxidation states, the presence of mixed valence oxides, and the complex multiplet splitting makes the deconvolution of $\mathrm{Mn} 2 \mathrm{p}$ region rather complicated (Fig. S1a in the ESI $\dagger$ ). ${ }^{52,53}$ For our purposes, an initial assessment of the average oxidation state of $\mathrm{Mn}$ on the surface was carried out by determining the peak separation of the Mn 2s peaks shown in Fig. S1b (ESI $\dagger$ ). The determined peak separation of $5.1 \mathrm{eV}$ is slightly lower than values determined for common Mn(III) compounds (5.4 eV for MnOOH or $5.5 \mathrm{eV}$ for $\left.\mathrm{Mn}_{2} \mathrm{O}_{3}\right)$. This signals that other compounds with different valence states are also present on the surface of the sample (e.g., $\mathrm{Mn}(\mathrm{Iv})$ with $4.4 \mathrm{eV}$ for $\mathrm{MnO}_{2}$ ). This value is in good agreement for the splitting of $\mathrm{Na}_{x} \mathrm{MnO}_{2}$ type compounds. ${ }^{54}$ Note, however, that care must be exercised with this approach, as it is not sufficient to reliably determine the chemical species present on the surface, and fitting of the Mn 2p peak must be carried out. ${ }^{53}$ The high-resolution $\mathrm{C}$ 1s spectra in Fig. S1c (ESI $\dagger$ ) can be attributed to the presence of adventitious carbon on the surface of the samples. The peaks $284.79 \mathrm{eV}$ refer to $\mathrm{C}-\mathrm{C}$ and $\mathrm{C}-\mathrm{H}$ states while those at $288.09 \mathrm{eV}$ and $286.14 \mathrm{eV}$ indicate the presence of $\mathrm{C}-\mathrm{OH}$ and $\mathrm{O}-\mathrm{C}=\mathrm{O}$ functionalities. The small amount of $\mathrm{K}^{+}$on the sample surface likely originates from the chemicals used during the synthesis procedure. The resolved high-resolution $\mathrm{O}$ 1s spectrum presented in Fig. S1d (ESI $\dagger$ ) shows two components, one originating from the lattice oxide $(529.73 \mathrm{eV})$ and the other originating from the presence of surface hydroxides (531.39 eV). Their position and comparable contribution suggest the prevalence of hydroxide species on the sample surface. ${ }^{53}$ In a following step, the fitting of the Mn $2 \mathrm{p}$

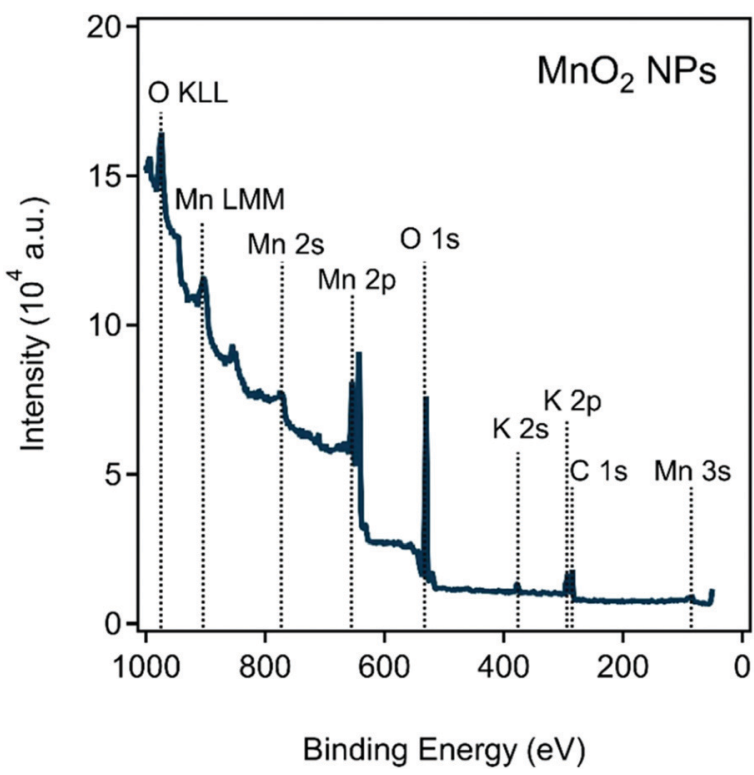

Fig. 1 XPS survey spectrum of the obtained $\mathrm{MnO}_{2} \mathrm{NPS}$. The $\mathrm{O} \mathrm{KLL}$ and Fe LMM represent Auger transitions involving energy levels $K, L$ and $M$. peak was carried considering the multiplet splitting of the species. $^{52}$ It was finally concluded that the surface primarily consists of $\mathrm{MnO}(\mathrm{OH})(64 \%)$ and $\mathrm{MnO}_{2}(36 \%)$ species.

The $\mathrm{pH}$-dependence of size and zeta potential of $\mathrm{MnO}_{2} \mathrm{NPs}$ is shown in Fig. 2a. In acidic and neutral $\mathrm{pH}$, the $\mathrm{MnO}_{2} \mathrm{NPs}$ undergo excessive and rapid aggregation and the hydrodynamic radii of aggregates exceeded $1.5 \mu \mathrm{m}$. Thus, these conditions are not suitable to obtain monodisperse particle dispersions for further experiments. As the $\mathrm{pH}$ becomes basic, the particle size decreased significantly, reaching a radius of $(83 \pm 2) \mathrm{nm}$ with a PDI of $11.9 \%$ at $\mathrm{pH} 9$ and remained the same within the experimental error until $\mathrm{pH} 11$.

These aggregation trends can be explained by observing the accompanying changes in zeta potentials. ${ }^{55}$ Accordingly, the particles have low absolute zeta potential less than $20 \mathrm{mV}$ up to $\mathrm{pH} 7$, where the electrostatic forces are overcome by the van der Waals forces. ${ }^{56}$ In basic medium, surface hydroxides are deprotonated, and at $\mathrm{pH} 9, \mathrm{MnO}_{2} \mathrm{NPs}$ acquire a high negative zeta potential of $(-37 \pm 1) \mathrm{mV}$, which is high enough for electrostatic repulsion forces to dominate. In Fig. $2 b$, the SL zeta potential and size dependence on the $\mathrm{pH}$ is shown. Throughout the $\mathrm{pH}$ range of $3-11$, the SL particles maintained an average hydrodynamic radius of $(432 \pm 16) \mathrm{nm}$, indicating high colloidal stability. The magnitude of the zeta potential increases gradually as the $\mathrm{pH}$ is increased owning to the increased deprotonation of the sulfate groups on the surface of SL. At pH 9, SL particles have a zeta potential of $(-65 \pm 1) \mathrm{mV}$ and a hydrodynamic radius of $(441 \pm 33) \mathrm{nm}$ with a PDI of 20.9\%. The dispersion characteristics of the $\mathrm{MnO}_{2} \mathrm{NPs}$ and SL particles at pH 9 are summarized in Table S2 (ESI $\dagger$ ).

The morphology of SL particles as well as $\mathrm{MnO}_{2}$ NPs was visualized via electron microscopy. The SEM and TEM images of SL particles, shown in Fig. S2a and b (ESI $\dagger$ ), respectively, feature the well-defined spherical morphology as well as the relatively low polydispersity of the prepared SL particles. On the other hand, $\mathrm{MnO}_{2}$ NPs show flaky morphology as shown in the SEM image in Fig. S2c (ESI $\dagger$ ). The aggregated state of the sample is attributed to drying process during SEM sample preparation. The TEM images of $\mathrm{MnO}_{2} \mathrm{NPs}$, shown in Fig. S2d-f (ESI $\dagger$ ), further feature the flaky nature of the $\mathrm{MnO}_{2}$ NPs. Note that the hydrodynamic sizes measured by DLS are slightly higher than those of the individual particles observed in the SEM and TEM images due to the polydispersity of the particles and the presence of trace aggregates in the samples, whose effect is more pronounced in the light scattering measurements.

\section{Homoaggregation of $\mathrm{SL}$ and $\mathrm{MnO}_{2} \mathrm{NPs}$}

The aggregation tendency of SL at different SL concentrations and 1.0 $\mathrm{M}$ ionic strength was carried out to optimize the experimental conditions for later aggregation rate measurements. By setting the background salt concentration at $1.0 \mathrm{M}$, all electrostatic repulsive forces are screened and thus, SL are expected to undergo rapid aggregation according to the Derjaguin, Landau, Verwey and Overbeek (DLVO) theory. ${ }^{57,58}$ As shown in Fig. 3a, the slopes of the linear fits of 

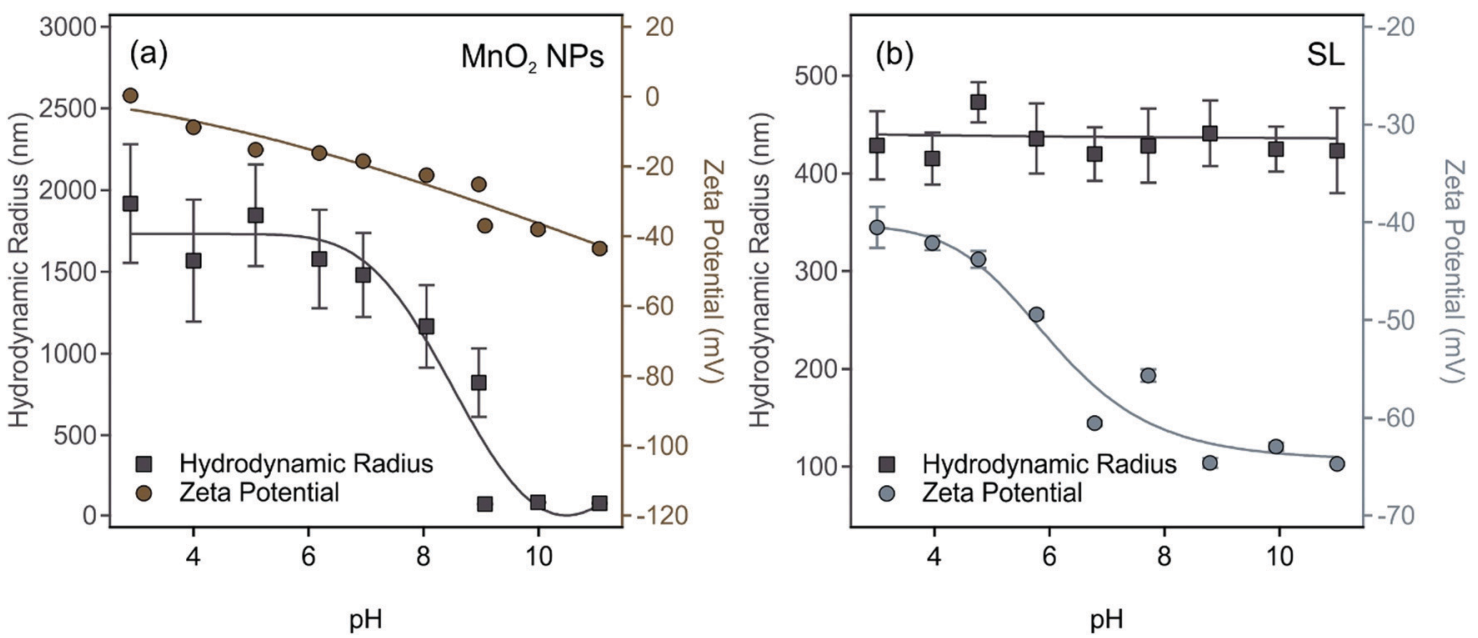

Fig. 2 The $\mathrm{pH}$ dependence of the hydrodynamic radius (squares) and zeta potential (circles) of (a) $\mathrm{MnO}_{2} \mathrm{NPs}$ and (b) $\mathrm{SL}$ particles. The concentration of the $\mathrm{MnO}_{2} \mathrm{NPs}$ and SL particles was 50 and 125 ppm, respectively, in the dispersions. The ionic strength was set to $1 \mathrm{mM}$. The lines are just to guide the eyes.

hydrodynamic radius versus time data increase when the concentration of SL was raised.

The apparent aggregation rate constants $\left(k_{\mathrm{app}}\right)$ as well as the aggregation half-time $\left(T_{1 / 2}\right)$ for the corresponding samples were calculated using eqn (2) and (3), respectively, which are plotted in Fig. $3 \mathrm{~b}$ as a function of the SL concentration. The data clearly show that $k_{\text {app }}$ increases and $T_{1 / 2}$ decreases with increasing particle concentration as a result of accelerated aggregation in concentrated samples. Moreover, in measurements such as those in Fig. 3a, the linear trends in the hydrodynamic radius-time data refer to early stage of aggregation and indicate the absence of higher ranked aggregates, which would cause deviation from linearity. ${ }^{46}$ Accordingly, a compromised SL concentration of $125 \mathrm{ppm}$ was used in further measurements, where early stage of aggregation can be followed, while the scattering intensity is high enough for reliable DLS measurements.

The salt-induced aggregation of both particles was also assessed at different ionic strengths. Eqn (1) was used to obtain the stability ratio values at the corresponding $\mathrm{NaCl}$ concentrations. As shown in Fig. 4, the stability ratio of SL significantly decreased as the ionic strength was increased until it reached unity at the critical coagulation concentration (CCC) of $250 \mathrm{mM}$, the concentration that separates slow and fast aggregation regimes. The DLVO theory states that the salt constituent ions screen the surface charge resulting in shrinking of the electric double layer and weakening of the repulsive electrostatic forces around SL particles. Thus, when salt concentrations equal or exceed the CCC, the van der Waals attractive forces dominate, and particles undergo diffusion-controlled aggregation.
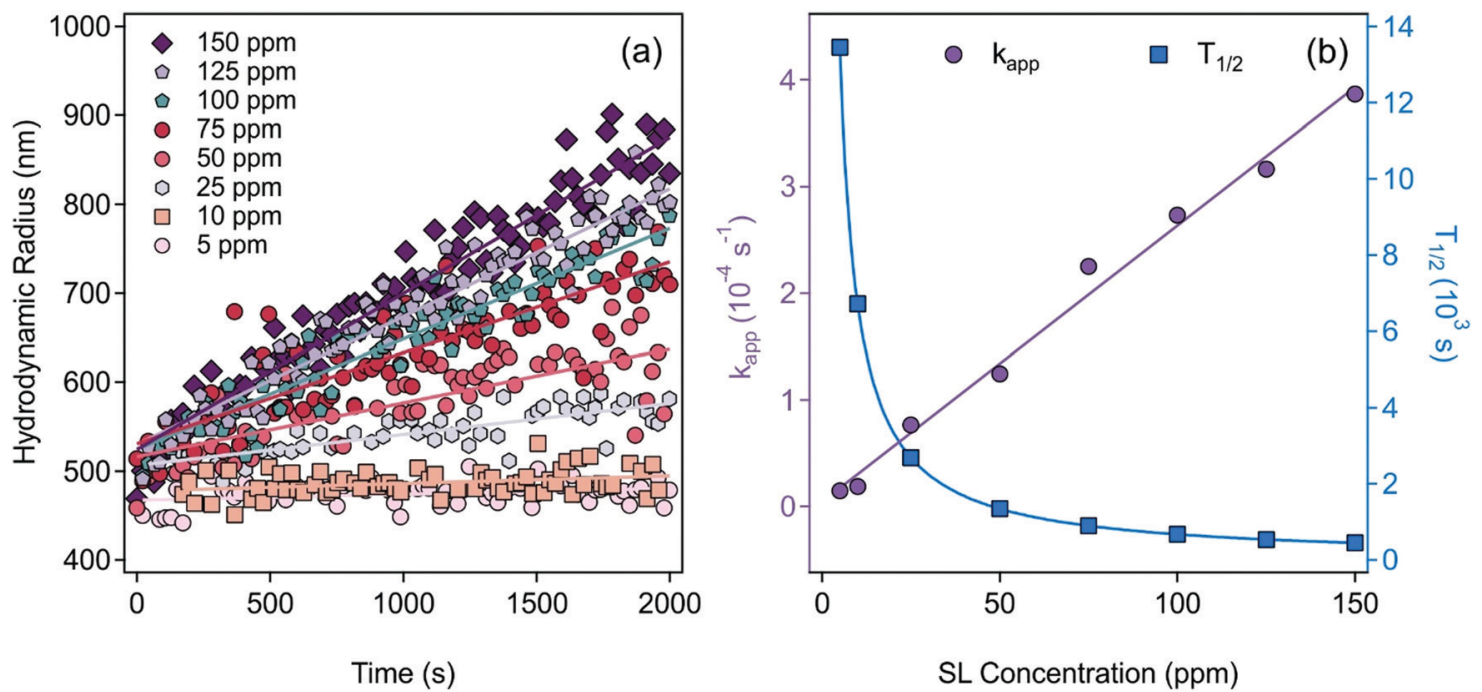

Fig. 3 (a) Time-resolved DLS measurements of SL at different concentrations at $1.0 \mathrm{M}$ ionic strength. The straight lines represent the linear fits used to calculate the apparent aggregation rate constants with eqn (2). (b) The apparent aggregation rate constant $\left(k_{\text {app }}\right)$ as well as the aggregation half-time $\left(T_{1 / 2}\right)$ at different particle concentrations, obtained via eqn (2) and (3), respectively. 


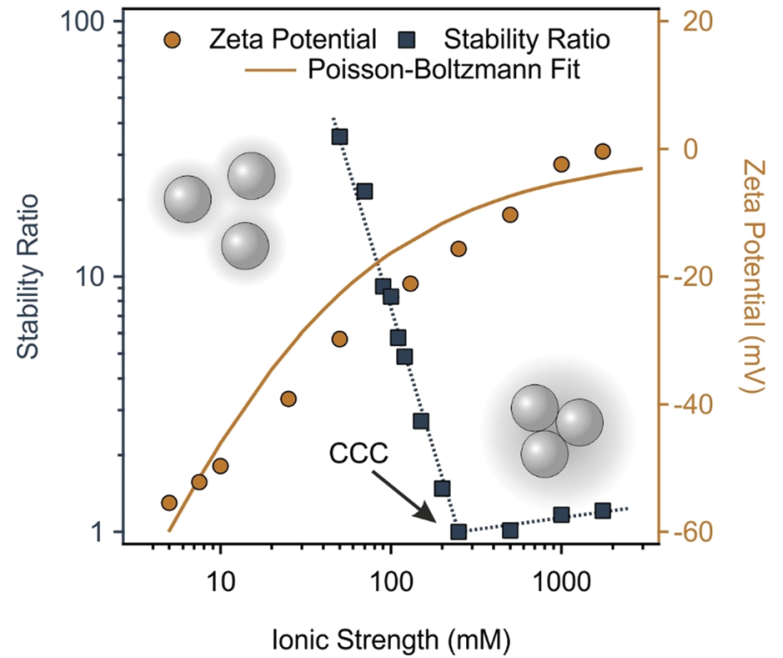

Fig. 4 Stability ratio (squares) and zeta potential (circles) values of SL particles as a function of the ionic strength. The $\mathrm{pH}$ was kept at 9 and the $\mathrm{SL}$ concentration was $125 \mathrm{ppm}$ in all samples. The dotted blue line only serves as eye guidance. The continuous gold line is the Poisson-Boltzmann fit.

Similar findings are reached when the accompanying changes in SL zeta potentials at different ionic strengths are measured. SL possesses high zeta potential at low salt levels due to the presence of the deprotonated sulfate groups. As more salt is introduced, the zeta potential around SL drops owing to surface charge screening. The Poisson-Boltzmann theory ${ }^{59}$ was used to fit the zeta potential data and a charge density of $-15.0 \mathrm{mC} \mathrm{m}^{-2}$ was determined at the slip plane (Table S2, ESI $\dagger$ ).

Similar tendencies can be seen for $\mathrm{MnO}_{2}$ NPs in Fig. 5. The increase in the ionic strength gradually decreased the stability ratio as well as the magnitude of zeta potential because of charge screening, and the subsequent predominance of van

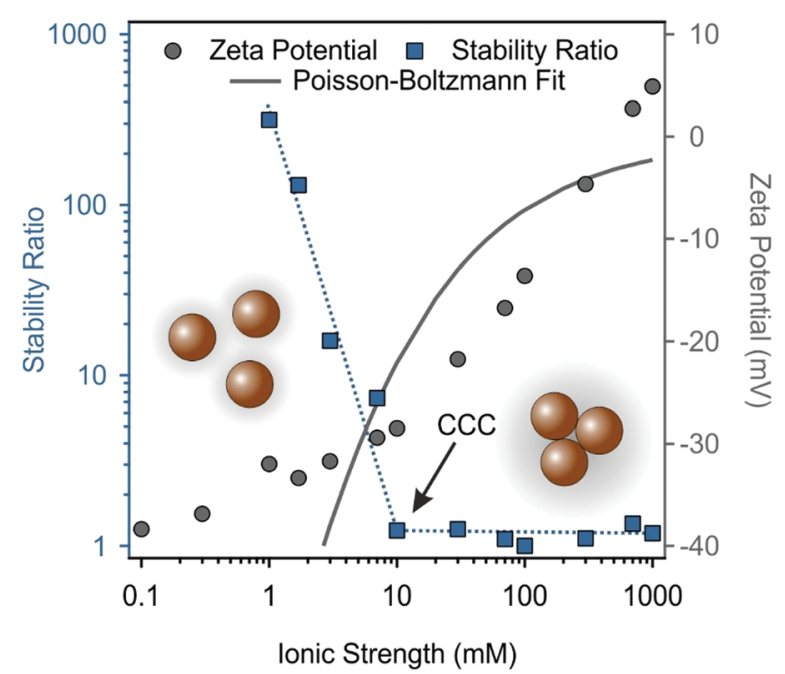

Fig. 5 Stability ratio (squares) and zeta potential (circles) values of $100 \mathrm{ppm} \mathrm{MnO}_{2}$ NPs dispersions as a function of the ionic strength. The $\mathrm{pH}$ was kept at 9 in all samples. The dotted blue line only serves as eye guidance. The continuous grey line is the Poisson-Boltzmann fit. der Waals forces. The CCC occurred at $10 \mathrm{mM}$, which indicates rather low colloidal stability of the bare $\mathrm{MnO}_{2}$ NPs. Upon fitting the zeta potential data with the Poisson-Boltzmann model, the resulting surface charge density of $\mathrm{MnO}_{2} \mathrm{NPs}$ was $-5.2 \mathrm{mC} \mathrm{m}^{-2}$. In Fig. 5, the Poisson-Boltzmann fit somewhat deviates from the $\mathrm{MnO}_{2}$ NPs zeta potential data points at low salt concentrations, which is attributed to the electrokinetic effect reported earlier. ${ }^{60}$ The surface charge density of the $\mathrm{MnO}_{2}$ NPs is significantly lower than the one determined for SL, which led to a higher CCC for SL in line with the prediction of the DLVO theory, since the resistance against salt-induced aggregation is stronger for particles of higher charge and thus, of stronger electrical double layer forces. Besides, the aggregation mechanism follows the prediction of the DLVO theory in both cases, similar to other charged colloidal particles dispersed in salt solutions. ${ }^{46,55,61-66}$

\section{PDADMAC functionalization of $\mathrm{MnO}_{2} \mathrm{NPs}$}

Since the aim was to attach $\mathrm{MnO}_{2}$ NPs to the SL surfaces, the charge balance must be changed to achieve opposite charges on the interacting particles. Accordingly, $\mathrm{MnO}_{2}$ NPs were functionalized with PDADMAC polyelectrolyte. It is well known that polyelectrolytes adsorb strongly on oppositely charged surfaces and other molecules, ${ }^{67,68}$ therefore, it was expected that the original negative sign of $\mathrm{MnO}_{2}$ NPs turns to positive after adding the appropriate amount of PDADMAC. Therefore, the precise dose was determined and fine-tuned so that the functionalized particles form stable dispersions. The zeta potential values of $\mathrm{MnO}_{2}$ NPs determined at different PDADMAC doses are shown in Fig. 6.

At low PDADMAC doses, the overall particle charge was negative, as indicated by the zeta potential values, which gradually increased as more PDADMAC was introduced. Around $20 \mathrm{mg}$ PDADMAC/g $\mathrm{MnO}_{2} \mathrm{NPs}$, the zeta potential approached zero. At the isoelectric point (IEP), the amount of

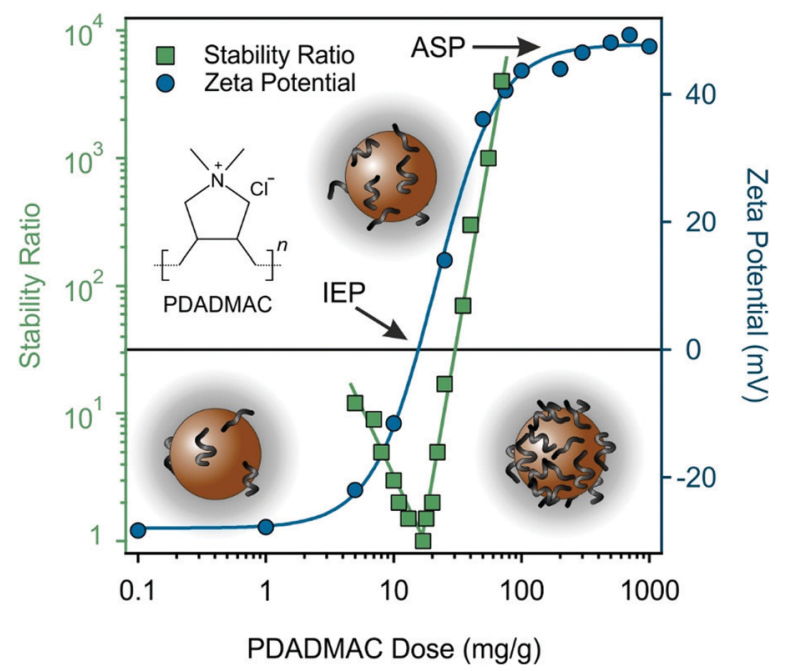

Fig. 6 Stability ratio (squares) and zeta potential (circles) values of $\mathrm{MnO}_{2}$ NPs at different PDADMAC doses. The ionic strength was $1 \mathrm{mM}$ and the $\mathrm{pH}$ was 9. The concentration of $\mathrm{MnO}_{2} \mathrm{NPs}$ was kept at $100 \mathrm{ppm}$. The solid lines serve as eye guidance. The polyelectrolyte concentration is expressed in mg PDADMAC per one gram of $\mathrm{MnO}_{2} \mathrm{NPs}$. 


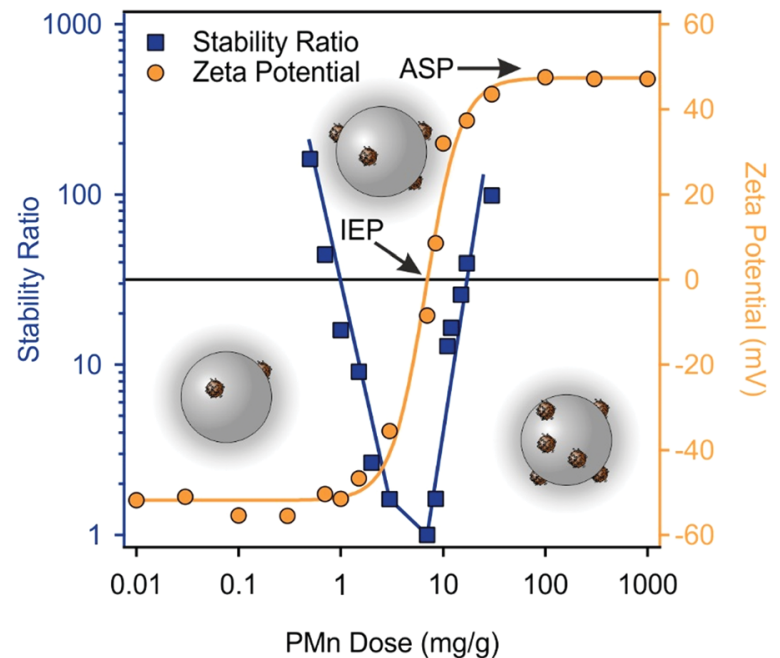

Fig. 7 Stability ratio (squares) and zeta potential (circles) values of SL particles in the presence of PMn at different concentrations. The concentration of SL was kept at $125 \mathrm{ppm}$, whereas the ionic strength was $1 \mathrm{mM}$ and the $\mathrm{pH}$ was 9 . The $\mathrm{mg} \mathrm{g}^{-1}$ unit refers to $\mathrm{mg} \mathrm{PMn}$ per one gram of SL. The solid lines serve as eye guidance only.

positive and negative charges are balanced and thus, the particles have zero net charge. Higher doses of PDADMAC resulted in charge reversal leading to positively charged particles. Similar charge reversal was reported earlier for oppositely charged particle-polyelectrolyte systems. ${ }^{64,66,69}$ The zeta potential reached a maximum value at the onset of the adsorption saturation plateau (ASP) at $100 \mathrm{mg} \mathrm{g}^{-1}$ dose, where the $\mathrm{MnO}_{2}$ NPs surface became saturated with adsorbed PDADMAC and further added polyelectrolytes remain dissolved in the solution. $^{70}$

Moreover, the stability ratios were measured under the same experimental conditions to assess the colloidal stability of the PDADMAC-functionalized $\mathrm{MnO}_{2}$ NPs dispersions. Fig. 6 shows that the gradual decrease in zeta potential values is paralleled with changes in the stability ratios. When the particles have high zeta potential (either positive or negative), the stability ratio values are large indicating stable dispersions. However, at PDADMAC doses around the IEP, the stability ratios drop to a value of one, which indicates rapid particle aggregation and unstable dispersions. Such a behavior is typical for oppositely charged particle-polyelectrolyte systems ${ }^{63,66,67}$ and qualitatively agrees with the prediction of the DLVO theory. ${ }^{57,58}$

Lastly, since the $\mathrm{MnO}_{2}$ NPs surface became saturated with PDADMAC at doses that occur at or beyond the onset of the zeta potential plateau, the particles prepared at $200 \mathrm{mg} \mathrm{g}^{-1}$ dose are denoted as PMn. At this experimental condition, the forming PMn possess high positive charge and high stability ratio and they are suitable for heteroaggregation with oppositely charged SL.

\section{Heteroaggregation of PMn with SL}

Based on the above results, oppositely charged PMn and SL particles were mixed in different ratios, while the concentration of negatively charged SL was kept at 125 ppm. In the resulting SPMn composite, the intensity of the scattered light originates mostly from SL particles rather than $\mathrm{MnO}_{2} \mathrm{NPs}$, as the magnitude of the intensity is proportional to the sixth power of the size of the scattering object, ${ }^{71}$ which is also evident from the scattering intensity data of individual particles in Table S2 (ESI $\dagger$ ). The zeta potential values at different PMn doses are shown in Fig. 7. At low doses, the overall charge of the particles is negative and slowly increased as more PMn were introduced into the system indicating their adsorption on the SL particles. The IEP occurred around a dose of $10 \mathrm{mg} \mathrm{g}^{-1}$, where the zeta potential approaches zero. Higher doses of PMn led to positively charged particles. Such a charge inversion is common in polyelectrolyte-particle systems as discussed before, nevertheless, it was rarely reported in dispersions containing oppositely charged particles. ${ }^{72,73}$ At and beyond $30 \mathrm{mg} \mathrm{g}^{-1}$, the zeta potential reached a maximum value, where SL surface most likely became saturated with adsorbed PMn at dose values corresponding to the onset of the ASP.

Stability ratios were determined under the same experimental conditions. As Fig. 7 shows, large magnitude of zeta potential in both in the negative and positive regimes corresponds to large stability ratio values indicating stable dispersions. However, at PMn doses around the IEP, the stability ratios approach unity indicating unstable dispersions. Several studies on latex particles have attributed the predominant interparticle forces to DLVOtype interaction, ${ }^{65,67,74}$ as discussed in the previous section. Thus, it is certain that the functionalization with PMn particles did not lead to the appearance of major additional interaction forces, and the aggregation mechanism is driven by the balance between DLVO type forces, namely, electrostatic double layer repulsion and van der Waals attraction. The latter one gradually predominates, when the overall charge of the particles approaches zero, i.e., around the IEP, while the particles are stabilized by electrostatic repulsion at doses below or above this point. SPMn refers to a composite of $100 \mathrm{mg}$ PMn per one gram of SL forming highly stable colloid.
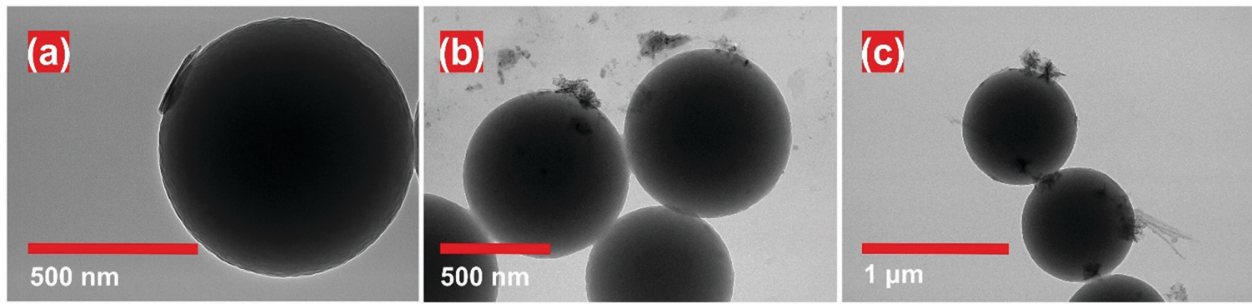

Fig. 8 TEM images of SPMn system at PMn doses of (a) $0.1 \mathrm{mg} \mathrm{g}^{-1}$, (b) $10 \mathrm{mg} \mathrm{g}^{-1}$, and (c) $100 \mathrm{mg} \mathrm{g}^{-1}$. 
(a)
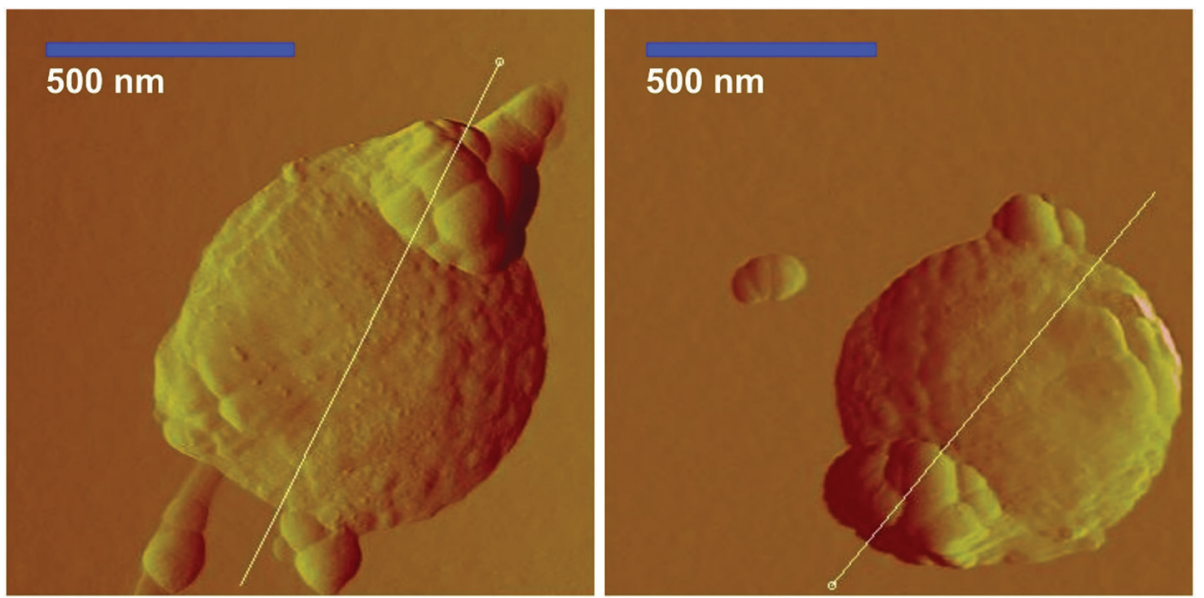

(b)
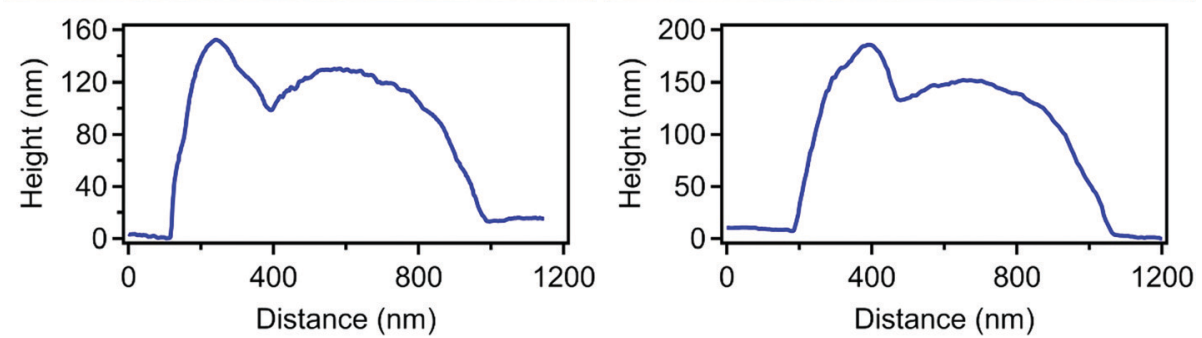

Fig. 9 (a) AFM amplitude images of SPMn deposited on a mica substrate as well as (b) the height profiles taken along the indicated white line.

The immobilization of PMn on SL was visualized by TEM images (Fig. 8), which were taken at PMn doses of 0.1, 10, and $100 \mathrm{mg} \mathrm{g}^{-1}$, corresponding to concentrations below, around, and above that at the IEP. The TEM sample preparation involves solvent removal, which typically leads to mild aggregation of the particles. However, the images clearly proved

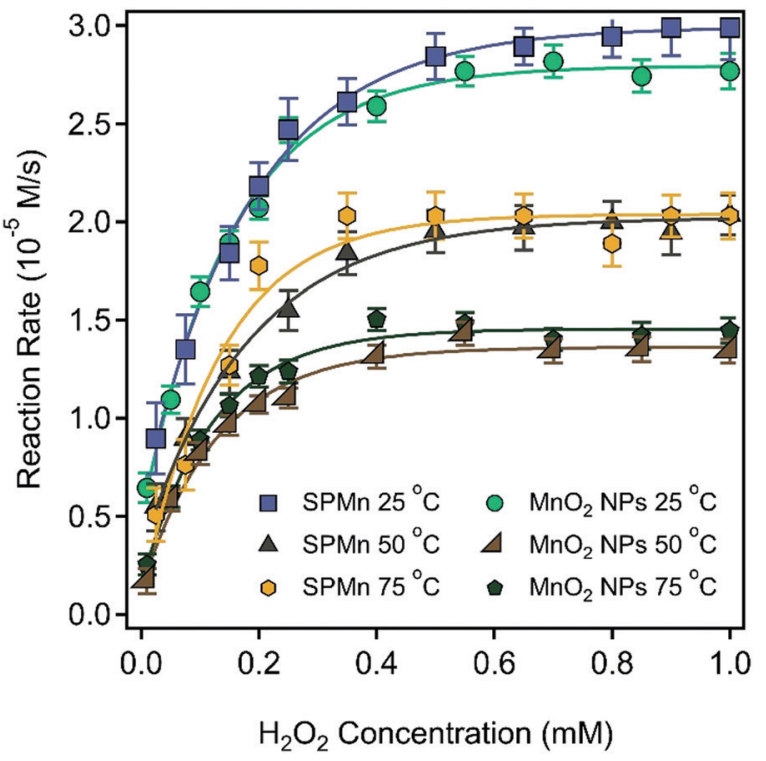

Fig. 10 CAT-like activity of $\mathrm{MnO}_{2} \mathrm{NPs}$ and SPMn at 25,50 , and $75^{\circ} \mathrm{C}$ for both materials. The particle concentrations were $10 \mathrm{ppm}$ and $100 \mathrm{ppm}$ (in $\mathrm{SL}$ ) for $\mathrm{MnO}_{2} \mathrm{NPs}$ and SPMn, respectively. The solid lines are the Michaelis-Menten fits described by eqn (4). the immobilization and increasing number of PMn can be observed on SL as the dose was increased in the samples.

In addition, the immobilization of PMn on SL was also visualized via AFM imaging. In these measurements, the SPMn sample was subjected to minimal changes due to simpler sample preparation, e.g., neither vacuum drying, nor metal coating is required. Fig. 9 shows the AFM images of SPMn (100 mg PMn/g SL, as indicated above) along with the height profiles.

The functionalized $\mathrm{MnO}_{2}$ NPs are clearly immobilized on the SL particles, forming antioxidant colloidal molecules. The height profile analysis also confirms the successful formation of the SPMn and indicates significantly different sizes for the component SL and PMn particles in accordance with the SEM and TEM images (Fig. S2, ESI $\dagger$ ).

\section{Antioxidant activity}

The CAT-like activity of the $\mathrm{MnO}_{2}$ NPs and SPMn particles was assessed via a standard assay, ${ }^{49}$ in which $\mathrm{H}_{2} \mathrm{O}_{2}$ breaks down in

Table 1 Comparison of the results of CAT and SOD activity assays obtained for the $\mathrm{MnO}_{2} \mathrm{NPs}$ and SPMn particles

\begin{tabular}{llll}
\hline Material & $K_{\mathrm{m}}{ }^{a}(\mathrm{mM})$ & $v_{\max }{ }^{a}\left(10^{-5} \mathrm{M} \mathrm{s}^{-1}\right)$ & $\mathrm{IC}_{50}{ }^{b}(\mathrm{ppm})$ \\
\hline $\mathrm{MnO}_{2} \mathrm{NPs}\left(25^{\circ} \mathrm{C}\right)$ & $0.083 \pm 0.011$ & $3.079 \pm 0.101$ & $0.274 \pm 0.012$ \\
$\mathrm{MnO}_{2} \mathrm{NPs}\left(50^{\circ} \mathrm{C}\right)$ & $0.082 \pm 0.008$ & $1.517 \pm 0.036$ & $0.132 \pm 0.005$ \\
$\mathrm{MnO}_{2} \mathrm{NPs}\left(75^{\circ} \mathrm{C}\right)$ & $0.074 \pm 0.010$ & $1.609 \pm 0.049$ & $0.192 \pm 0.010$ \\
$\mathrm{SPMn}\left(25^{\circ} \mathrm{C}\right)$ & $0.099 \pm 0.010$ & $3.323 \pm 0.079$ & $0.311 \pm 0.013$ \\
$\mathrm{SPMn}^{\circ}\left(50^{\circ} \mathrm{C}\right)$ & $0.118 \pm 0.017$ & $2.314 \pm 0.085$ & $0.271 \pm 0.012$ \\
$\left.\mathrm{SPMn}^{\circ} 75^{\circ} \mathrm{C}\right)$ & $0.106 \pm 0.025$ & $2.377 \pm 0.139$ & $0.417 \pm 0.017$
\end{tabular}

${ }^{a}$ Calculated by eqn (4). ${ }^{b}$ Determined in SOD activity assays. 

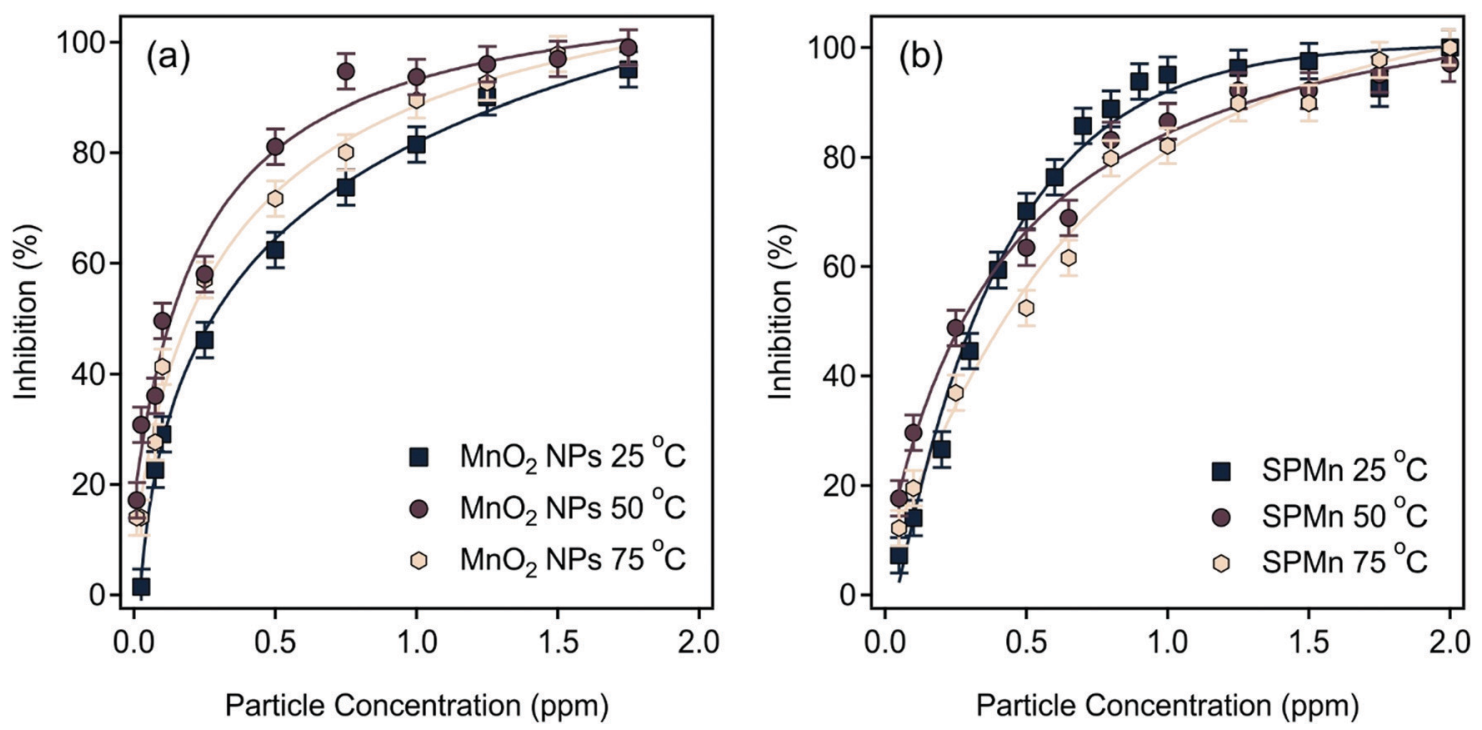

Fig. 11 Inhibition of the NBT-superoxide radical ion reaction by (a) $\mathrm{MnO}_{2} \mathrm{NPs}$ as well as (b) SPMn determined at $25^{\circ} \mathrm{C}$ (squares), $50{ }^{\circ} \mathrm{C}$ (circles), and $75^{\circ} \mathrm{C}$ (hexagons). The inhibition values were calculated using eqn (5). The solid lines are mathematical functions to interpolate the $\mathrm{IC}_{50}$ values.

the presence of the enzyme or its mimic. The reaction rates versus concentration data points determined at different temperatures are plotted in Fig. 10.

One can notice that the experimental points can be well fitted with the Michaelis-Menten model (eqn (4)) ${ }^{50}$ and the $K_{\mathrm{m}}$ and $v_{\max }$ values were determined from the fits in all cases (Table 1). The $v_{\max }$ is the maximum reaction rate observed, where higher $\mathrm{H}_{2} \mathrm{O}_{2}$ concentrations do not increase the rate any further, which can be attributed to the saturation of the catalytic sites. The $K_{\mathrm{m}}$ is the $\mathrm{H}_{2} \mathrm{O}_{2}$ concentration that correspond to the rate half that of the $v_{\max }$. The $K_{\mathrm{m}}$ value is a measure of the affinity between the catalyst and the substrate, where a lower $K_{\mathrm{m}}$ value indicates a higher affinity between the enzyme-like material and the substrate.

The results obtained revealed that the immobilization had no effect on the activity of $\mathrm{MnO}_{2} \mathrm{NPs}$, as evident by the close $K_{\mathrm{m}}$ and $v_{\max }$ values of SPMn and $\mathrm{MnO}_{2}$ NPs determined at $25{ }^{\circ} \mathrm{C}$. In other words, neither the PDADMAC functionalization nor the attachment to SL altered the $\mathrm{H}_{2} \mathrm{O}_{2}$ decomposition ability of $\mathrm{MnO}_{2}$ NPs. Moreover, the CAT activity of both $\mathrm{MnO}_{2}$ NPs and SPMn was obtained after the corresponding stock dispersions were thermally treated by immersion in a water bath at $50{ }^{\circ} \mathrm{C}$ and $75{ }^{\circ} \mathrm{C}$ for $90 \mathrm{~min}$, and subsequent cooling to room temperature. As shown in Fig. 10, thermal treatment resulted in a decrease in the CAT activity of both $\mathrm{MnO}_{2}$ NPs and SPMn compared to the untreated counterparts. The data indicate that the reduction of CAT activity was the same regardless of the temperature imposed, but the loss is more emphasized for $\mathrm{MnO}_{2}$ NPs than for SPMn. However, no unambiguous explanation can be given for the reason of such decrease based on the present experimental data. Comparatively, the native CAT completely loses its activity at $70{ }^{\circ} \mathrm{C}$ after 30 min heating. ${ }^{75}$ Although the thermal treatment also affected the activity of SPMn particles, they can still be considered as very active catalysts in $\mathrm{H}_{2} \mathrm{O}_{2}$ decomposition, which shows that SPMn had remarkable thermal and structural stability, making it a versatile candidate as antioxidant material in industrial processes for instance, where higher temperature is applied. The ability of the $\mathrm{MnO}_{2} \mathrm{NPs}$ and SPMn to dismutase superoxide radical ions was tested by the Fridovich assay. ${ }^{51}$ The inhibition of the NBT-radical reaction was calculated using eqn (5) and plotted as a function of the $\mathrm{MnO}_{2}$ NPs or SPMn concentration in Fig. 11.

The $\mathrm{IC}_{50}$ values for $\mathrm{MnO}_{2}$ NPs and SPMn were very similar at $25{ }^{\circ} \mathrm{C}$ (Table 1), but higher than the $\mathrm{IC}_{50}$ for native SOD $(0.07 \mathrm{ppm}) .{ }^{63}$ Thus, the functional integrity of $\mathrm{MnO}_{2} \mathrm{NPs}$ was kept upon polyelectrolyte functionalization and immobilization on SL. It is evident from the data of the heated samples that, unlike the CAT activity, there is no loss in SOD activity of either bare or immobilized $\mathrm{MnO}_{2}$ NPs, even though the composite were thermally treated in a water bath at $50{ }^{\circ} \mathrm{C}$ and $75{ }^{\circ} \mathrm{C}$ for $90 \mathrm{~min}$. The native SOD enzyme, however, was reported to lose its activity after $20 \mathrm{~min}$ at elevated temperatures. ${ }^{62}$ These results clearly indicate that the $\mathrm{MnO}_{2} \mathrm{NPs}$ possess remarkable antioxidant potential, with preserved activity and excellent colloidal stability upon immobilization.

\section{Conclusions}

$\mathrm{MnO}_{2}$ NPs with antioxidant activity were synthesized, functionalized with PDADMAC, and immobilized on SL particles. Heteroaggregation was rationalized as an adsorption process of the PMn particles on the SL surface due to their opposite charges. The positively charged PMn particles adsorbed strongly on the SL leading to charge neutralization and charge reversal at the appropriate PMn doses. The colloidal stability of the samples was assessed, and the findings confirmed that the aggregation in the PMn-SL systems is driven by DLVO-type forces. Accordingly, the electrostatic double layer repulsion stabilizes the dispersions at low and high PMn doses, where 
the particles possess significant charge. Near the IEP, however, the dispersions were unstable and diffusion-controlled aggregation occurred due to the lack of charges, i.e., to the disappearance of the electrostatic double layers and predominance of attractive van der Waals forces. The SPMn hybrid showed excellent colloidal and functional stabilities. The CAT-like activity of $\mathrm{MnO}_{2}$ NPs was maintained, although decreased, upon immobilization on SL and upon heating up to $75^{\circ} \mathrm{C}$, as indicated by the similarity of Michaelis-Menten parameters for both particles. The results of the SOD-like activity measurements implied no loss in $\mathrm{MnO}_{2}$ NPs activity upon immobilization or heating, as similar $\mathrm{IC}_{50}$ values were determined. These facts indicate that the obtained SPMn composites can be effectively used to combat reactive oxygen species in heterogeneous systems due to the excellent colloidal stability of the SPMn hybrid.

\section{Conflicts of interest}

There are no conflicts to declare.

\section{Acknowledgements}

Financial support from the Ministry of Human Capacities (20391-3/2018/FEKUSTRAT) and the Eötvös Lóránd Research Network (96130) is gratefully acknowledged. V. H. is supported by the Premium Postdoctoral Research Program (PPD-461042). The support from the University of Szeged Open Access Fund (5359) is gratefully acknowledged.

\section{References}

1 X. Ma, A. C. Hortelao, T. Patino and S. Sanchez, ACS Nano, 2016, 10, 9111-9122.

2 Y. H. Lin, J. S. Ren and X. G. Qu, Acc. Chem. Res., 2014, 47, 1097-1105.

3 K. Kirkorian, A. Ellis and L. J. Twyman, Chem. Soc. Rev., 2012, 41, 6138-6159.

4 H. Wei and E. K. Wang, Chem. Soc. Rev., 2013, 42, 6060-6093.

5 J. S. Mu, L. Zhang, G. Y. Zhao and Y. Wang, Phys. Chem. Chem. Phys., 2014, 16, 15709-15716.

6 J. J. X. Wu, X. Y. Wang, Q. Wang, Z. P. Lou, S. R. Li, Y. Y. Zhu, L. Qin and H. Wei, Chem. Soc. Rev., 2019, 48, 1004-1076.

7 S. I. Tsekhmistrenko, V. S. Bityutskyy, O. S. Tsekhmistrenko, V. M. Polishchuk, S. A. Polishchuk, N. V. Ponomarenko, Y. O. Melnychenko and M. Y. Spivak, Regul. Mech. Biosyst., 2018, 9, 469-476.

8 S. Murath, N. B. Alsharif, S. Saringer, B. Katana, Z. Somosi and I. Szilagyi, Crystals, 2020, 10, 148.

9 B. Bhushan and P. Gopinath, J. Mater. Chem. B, 2015, 3, 4843-4852.

10 D. Wang, X. L. Song, P. Li, X. J. J. Gao and X. F. Gao, J. Mater. Chem. B, 2020, 8, 9028-9034.
11 X. J. Wu, T. M. Chen, J. X. Wang and G. W. Yang, J. Mater. Chem. B, 2018, 6, 105-111.

12 H. Tokuyama, S. Yamago, E. Nakamura, T. Shiraki and Y. Sugiura, J. Am. Chem. Soc., 1993, 115, 7918-7919.

13 L. L. Dugan, J. K. Gabrielsen, S. P. Yu, T. S. Lin and D. W. Choi, Neurobiol. Dis., 1996, 3, 129-135.

14 H. Jiang, Z. H. Chen, H. Y. Cao and Y. M. Huang, Analyst, 2012, 137, 5560-5564.

15 W. W. He, Y. T. Zhou, W. G. Warner, X. N. Hu, X. C. Wu, Z. Zheng, M. D. Boudreau and J. J. Yin, Biomaterials, 2013, 34, 765-773.

16 M. Moglianetti, E. De Luca, P. A. Deborah, R. Marotta, T. Catelani, B. Sartori, H. Amenitsch, S. F. Retta and P. P. Pompa, Nanoscale, 2016, 8, 3739-3752.

17 L. Rastogi, D. Karunasagar, R. B. Sashidhar and A. Giri, Sens. Actuators, B, 2017, 240, 1182-1188.

18 J. S. Mu, L. Zhang, M. Zhao and Y. Wang, ACS Appl. Mater. Interfaces, 2014, 6, 7090-7098.

19 C. Murugan, N. Murugan, A. K. Sundramoorthy and A. Sundaramurthy, Chem. Commun., 2019, 55, 8017-8020.

20 W. Chen, J. Chen, A. L. Liu, L. M. Wang, G. W. Li and X. H. Lin, ChemCatChem, 2011, 3, 1151-1154.

21 S. Ghosh, P. Roy, N. Karmodak, E. D. Jemmis and G. Mugesh, Angew. Chem., Int. Ed., 2018, 57, 4510-4515.

22 Z. H. Dai, S. H. Liu, J. C. Bao and H. X. Jui, Chem. - Eur. J., 2009, 15, 4321-4326.

23 T. M. Chen, H. Zou, X. J. Wu, C. C. Liu, B. Situ, L. Zheng and G. W. Yang, ACS Appl. Mater. Interfaces, 2018, 10, 12453-12462.

24 T. R. Lin, L. S. Zhong, Z. P. Song, L. Q. Guo, H. Y. Wu, Q. Q. Guo, Y. Chen, F. F. Fu and G. N. Chen, Biosens. Bioelectron., 2014, 62, 302-307.

25 L. F. Wang, Y. Li, L. Zhao, Z. J. Qi, J. Y. Gou, S. Zhang and J. Z. Zhang, Nanoscale, 2020, 12, 19516-19535.

26 S. W. Wu, M. Qiu, B. C. Guo, L. Q. Zhang and Y. Lvov, ACS Sustainable Chem. Eng., 2017, 5, 1775-1783.

27 W. Li, Z. Liu, C. Q. Liu, Y. J. Guan, J. S. Ren and X. G. Qu, Angew. Chem., Int. Ed., 2017, 56, 13661-13665.

28 N. Singh, M. A. Savanur, S. Srivastava, P. D'Silva and G. Mugesh, Angew. Chem., Int. Ed., 2017, 56, 14267-14271.

29 W. Chen, Y. Y. Yan, R. L. Han, J. Hu, Y. F. Hou and K. Q. Tang, Photochem. Photobiol. Sci., 2021, 20, 153-160.

30 L. T. Yang, S. T. D. Chueng, Y. Li, M. Patel, C. Rathnam, G. Dey, L. Wang, L. Cai and K. B. Lee, Nat. Commun., 2018, 9, 3147.

31 G. Dey, L. T. Yang, K. B. Lee and L. Wang, J. Phys. Chem. C, 2018, 122, 29017-29027.

32 M. Sawangphruk, P. Srimuk, P. Chiochan, A. Krittayavathananon, S. Luanwuthi and J. Limtrakul, Carbon, 2013, 60, 109-116.

33 K. G. Lee, J. M. Jeong, S. J. Lee, B. Yeom, M. K. Lee and B. G. Choi, Ultrason. Sonochem., 2015, 22, 422-428.

34 D. R. Hu, L. J. Chen, Y. Qu, J. R. Peng, B. Y. Chu, K. Shi, Y. Hao, L. Zhong, M. Y. Wang and Z. Y. Qian, Theranostics, 2018, 8, 1558-1574.

35 S. J. Yao, S. Yuan, J. H. Xu, Y. Wang, J. L. Luo and S. S. Hu, Appl. Clay Sci., 2006, 33, 35-42. 
36 D. Gu, J. C. Tseng, C. Weidenthaler, H. J. Bongard, B. Spliethoff, W. Schmidt, F. Soulimani, B. M. Weckhuysen and F. Schuth, J. Am. Chem. Soc., 2016, 138, 9572-9580.

37 T. Takashima, K. Hashimoto and R. Nakamura, J. Am. Chem. Soc., 2012, 134, 1519-1527.

38 M. Cheng, Y. Yu, W. D. Huang, M. Fang, Y. Chen, C. M. Wang, W. L. Cai, S. Y. Zhang, W. X. Wang and W. J. Yan, ACS Biomater. Sci. Eng., 2020, 6, 4985-4992.

39 T. Sasaki, J. Ceram. Soc. Jpn., 2007, 115, 9-16.

40 T. C. Cao, M. Borkovec and G. Trefalt, Colloids Interfaces, 2020, 4, 52.

41 X. N. Wang, S. Wang, X. L. Pan and G. M. Gadd, Chemosphere, 2019, 221, 486-492.

42 O. Ben Moussa, L. Tinat, X. J. Jin, W. Baaziz, O. Durupthy, C. Sayag and J. Blanchard, ACS Catal., 2018, 8, 6071-6078.

43 J. M. Lopez-Lopez, A. Schmitt, A. Moncho-Jorda and R. Hidalgo-Alvarez, Adv. Colloid Interface Sci., 2009, 147, 186-204.

44 X. Du and J. H. He, J. Appl. Polym. Sci., 2008, 108, 1755-1760.

45 A. V. Delgado, E. Gonzalez-Caballero, R. J. Hunter, L. K. Koopal and J. Lyklema, Pure Appl. Chem., 2005, 77, 1753-1805.

46 H. Holthoff, S. U. Egelhaaf, M. Borkovec, P. Schurtenberger and H. Sticher, Langmuir, 1996, 12, 5541-5549.

47 G. Trefalt, I. Szilagyi, T. Oncsik, A. Sadeghpour and M. Borkovec, Chimia, 2013, 67, 772-776.

48 M. Elimelech, J. Gregory, X. Jia and R. A. Williams, Particle deposition and aggregation: measurement, modeling, and simulation, Butterworth-Heinemann Ltd, Oxford, 1995.

49 A. C. Maehly and B. Chance, Methods Biochem. Anal., 1954, 1, 357-424.

50 K. A. Johnson and R. S. Goody, Biochemistry, 2011, 50, 8264-8269.

51 C. Beaucham and I. Fridovich, Anal. Biochem., 1971, 44, 276-287.

52 M. C. Biesinger, B. P. Payne, A. P. Grosvenor, L. W. M. Lau, A. R. Gerson and R. S. Smart, Appl. Surf. Sci., 2011, 257, 2717-2730.

53 E. S. Ilton, J. E. Post, P. J. Heaney, F. T. Ling and S. N. Kerisit, Appl. Surf. Sci., 2016, 366, 475-485.

54 J. Y. Li, X. L. Wu, X. H. Zhang, H. Y. Lu, G. Wang, J. Z. Guo, F. Wan and R. S. Wang, Chem. Commun., 2015, 51, 14848-14851.
55 M. Galli, S. Saringer, I. Szilagyi and G. Trefalt, Colloids Interfaces, 2020, 4, 20.

$56 \mathrm{~J}$. Israelachvili, Intermolecular and surface forces, Academic Press, London, 3rd edn, 2011.

57 E. J. W. Verwey and J. T. G. Overbeek, Theory of stability of lyophobic colloids, Elsevier, Amsterdam, 1948.

58 B. Derjaguin and L. D. Landau, Acta Physicochim. URSS, 1941, 14, 633-662.

59 D. F. Evans and H. Wennerstrom, The colloidal domain, John Wiley, New York, 1999.

60 M. Borkovec, S. H. Behrens and M. Semmler, Langmuir, 2000, 16, 5209-5212.

61 J. Hierrezuelo, A. Sadeghpour, I. Szilagyi, A. Vaccaro and M. Borkovec, Langmuir, 2010, 26, 15109-15111.

62 M. Pavlovic, M. Nafradi, P. Rouster, S. Murath and I. Szilagyi, J. Colloid Interface Sci., 2019, 543, 174-182.

63 M. Pavlovic, P. Rouster and I. Szilagyi, Nanoscale, 2017, 9, 369-379.

64 P. Rouster, M. Pavlovic, S. Saringer and I. Szilagyi, J. Phys. Chem. C, 2018, 122, 11455-11463.

65 S. Saringer, R. A. Akula, A. Szerlauth and I. Szilagyi, J. Phys. Chem. B, 2019, 123, 9984-9991.

66 S. Saringer, P. Rouster and I. Szilagyi, Langmuir, 2019, 35, 4986-4994.

67 I. Szilagyi, G. Trefalt, A. Tiraferri, P. Maroni and M. Borkovec, Soft Matter, 2014, 10, 2479-2502.

68 K. Kolman, O. Nechyporchuk, M. Persson, K. Holmberg and R. Bordes, Colloids Surf., A, 2017, 532, 420-427.

69 L. Avadiar and Y. K. Leong, Colloid Polym. Sci., 2011, 289, 237-245.

70 E. Seyrek, J. Hierrezuelo, A. Sadeghpour, I. Szilagyi and M. Borkovec, Phys. Chem. Chem. Phys., 2011, 13, 12716-12719.

71 M. I. Mishchenko, L. D. Travis and A. A. Lacis, Scattering, absorption, and emission of light by small particles, University Press, Cambridge, 2002.

72 N. B. Alsharif, G. F. Samu, S. Sáringer, S. Muráth and I. Szilagyi, J. Mol. Liq., 2020, 309, 113066.

73 M. Pavlovic, P. Rouster, E. Bourgeat-Lami, V. Prevot and I. Szilagyi, Soft Matter, 2017, 13, 842-851.

74 F. J. M. Ruiz-Cabello, G. Trefalt, T. Oncsik, I. Szilagyi, P. Maroni and M. Borkovec, J. Phys. Chem. B, 2015, 119, 8184-8193.

75 A. Dincer and T. Aydemir, J. Enzyme Inhib., 2001, 16, 165-175. 